AperTO - Archivio Istituzionale Open Access dell'Università di Torino

\title{
Cerium-Doped Zirconium Dioxide, a Visible-Light-Sensitive Photoactive Material of Third Generation
}

\section{This is the author's manuscript}

Original Citation:

Availability:

This version is available http://hdl.handle.net/2318/141649

since 2016-01-07T17:33:53Z

Published version:

DOI:10.1021/jz402731s

Terms of use:

Open Access

Anyone can freely access the full text of works made available as "Open Access". Works made available under a Creative Commons license can be used according to the terms and conditions of said license. Use of all other works requires consent of the right holder (author or publisher) if not exempted from copyright protection by the applicable law. 


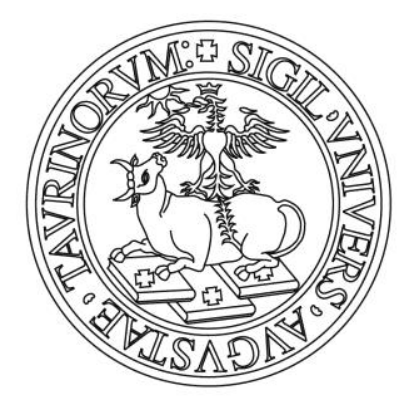

\section{UNIVERSITÀ DEGLI STUDI DI TORINO}

This is an author version of the contribution published on:

Questa è la versione dell'autore dell'opera:

Journal of Physical Chemistry Letters, 2014, 5, 447451 doi.org/10.1021/jz402731s

Chiara Gionco, Maria C. Paganini, Elio Giamello, Robertson Burgess Cristiana Di Valentin, and Gianfranco Pacchioni

The definitive version is available at:

La versione definitiva è disponibile alla URL:

http://pubs.acs.org/journal/jpclcd 


\section{Cerium Doped Zirconium Dioxide, a Visible-Light}

\section{Sensitive Photoactive Material of Third Generation}

Chiara Gionco $^{1}$, Maria C. Paganini ${ }^{1}$, Elio Giamello ${ }^{1 *}$, Robertson Burgess $^{2}$, Cristiana Di $^{2}$

Valentin $^{2}$, Gianfranco Pacchioni ${ }^{2}$.

${ }^{1}$ Dipartimento di Chimica, Università di Torino and NIS, Nanostructured Interfaces and

Surfaces, Via P. Giuria 7, 10125 Torino, Italy

${ }^{2}$ Dipartimento di Scienza dei Materiali, Università di Milano-Bicocca, Via R. Cozzi, 53, 20125, Milano, Italy

If more than one address, use symbols to match author names to address(es).

AUTHOR INFORMATION

Corresponding Author

* elio.giamello@unito.it.

\section{Present Addresses}

$\dagger$ If an author's address is different than the one given in the affiliation line, this information may be included here. 
ABSTRACT. The dispersion of small amounts of $\mathrm{Ce}^{4+}$ ions in the bulk of $\mathrm{ZrO}_{2}$ leads to a photoactive material sensitive to visible light. This is shown monitoring by EPR the formation and the reactivity of photogenerated $(\lambda>420 \mathrm{~nm})$ charge carriers. The effect, as confirmed by DFT calculations, is due to the presence in the solid of empty $4 \mathrm{f}$ Ce states at mid gap which act as intermediate levels in a double excitation mechanism. This solid can be considered an example of third generation photoactive material.

\section{TOC GRAPHICS}

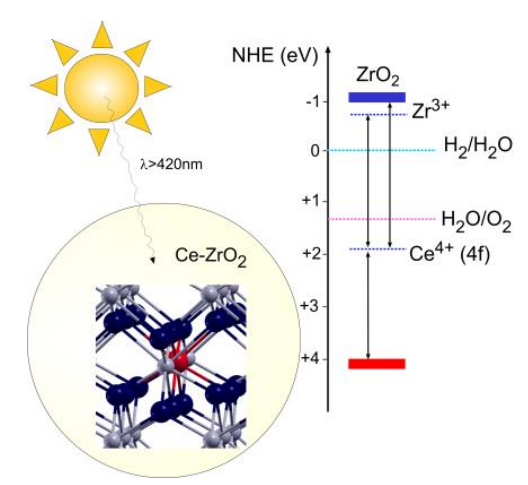

KEYWORDS Charge separation, DFT, EPR spectroscopy, Third generation photoactive systems. 
Photocatalytic reactions have enormous importance in modern environmental chemistry (oxidative removal of pollutants of emergent concern) ${ }^{1}$ and energetics ${ }^{2}$. In particular, the photoelectrochemical splitting of water achieved by Fujishima and Honda in $1972^{3}$ using a $\mathrm{TiO}_{2}$ photoanode paved the avenue to a new, stimulating research branch known as artificial photosynthesis ${ }^{4}$. Pristine $\mathrm{TiO}_{2}$ is even now the dominant system in environmental applications and consequently the undisputed player of the so-called first generation of photoactive materials ${ }^{5}$, ${ }^{6}$. Semiconducting oxides owe their photoactivity to the ability of exciting electrons, under irradiation with light of suitable frequency, from the valence band (VB) to the conduction band (CB) thereby creating holes in the valence band itself ${ }^{7}$. Due to their reductive (electrons) and oxidative (holes) potentials the photoexcited charge carriers, once they reach the surface, are able to entail redox chemical reactions. The limitation of this approach relies in the irreconcilable divergence between the width of the oxide band gap and the redox potential of the excited charge carriers. By increasing the band gap of the oxide, the electrochemical potentials of excited electrons and holes become more effective, but, at the same time, photoexcitation implies to use photons of higher energy. Pristine $\mathrm{TiO}_{2}$ is efficient in decomposing pollutants under irradiation with ultraviolet light (band gap around $3.2 \mathrm{eV}$ ) but is poorly effective under sunlight as this contains prevalently visible and near-infrared (NIR) radiation.

Photoactive solid systems capable to use visible light for the charge separation have been the target of a continuous search during the past twenty years. The research has mainly focused on the modifications of $\mathrm{TiO}_{2}$ via doping with transition metal ions ${ }^{8}$, p-block elements ${ }^{9-11}$, or supported metal nanoparticles ${ }^{12}$ having plasmonic effects. All these systems constitute the body of the so called second generation photoactive materials ${ }^{5}$ based on titanium dioxide. In general, however, to this generation belong also other and even more complex materials. 
The possible role in photocatalytic phenomena of other oxides having appropriate flat-band potentials, has been partly neglected in the past. Zirconium dioxide, for instance, a ceramic material also used as heterogeneous catalysts, has found only few applications in photocatalysis ${ }^{13}$ because of its large band gap $(c a .5 .0 \mathrm{eV})$, an energy corresponding to a negligible fraction of the solar light at earth surface.

In the present paper we show that materials based on $\mathrm{ZrO}_{2}$ modified by dispersion of $\mathrm{Ce}^{4+}$ ions in the bulk become photosensitive to visible light. This effect is due to the interplay between the energy levels of the two components. The photoactivity of the solids has been investigated mainly via Electron Paramagnetic Resonance (EPR) monitoring the formation of both charge carriers (electrons and holes) and $\mathrm{OH}$ radicals under irradiation with visible frequencies. DFT calculations provide a rational of the change in electronic structure and optical properties upon $\mathrm{Ce}$ doping. The $\mathrm{Ce}-\mathrm{ZrO}_{2}$ system here described is probably the first example of third generation photoactive materials based on a double excitation through localized intra-bandgap states, a mechanism recently proposed by Serpone et al. and still waiting for experimental confirmation ${ }^{5}$ 6.

The $\mathrm{CeO}_{2}$ molar fraction of the mixed oxide employed for the present investigation is $0.5 \%$ (CZ05). This material will be hereafter labeled as CZ05. Samples of the two bare oxides were also prepared and used to compare their properties with those of the mixed oxide.

For the mixed sample two phases have been identified by XRD analysis (S.I.): tetragonal (t) and monoclinic (m) zirconia (Table 1). The fraction of monoclinic phase is higher for Ce-doped $\mathrm{ZrO}_{2}$ than that found for the pure phase probably because a partial disorder in the structure is induced by Ce addition. 
Table 1. Weight percentage (\%wt) and crystallite size (d) obtained from Rietveld refinement of the XRD patterns of bare and mixed Ce-Zr oxides. SBET is the surface area derived from nitrogen adsorption measurements

$\begin{array}{ccccc}\text { Sample } & \text { Phase } & \% w t & \mathrm{~d}(\mathrm{~nm}) & \mathrm{S}_{\mathrm{BET}}\left(\mathrm{m}^{2} / \mathrm{g}\right) \\ \mathrm{ZrO}_{2} & \mathrm{t}-\mathrm{ZrO}_{2} & 78 & 15 & 150 \\ & \mathrm{~m}-\mathrm{ZrO}_{2} & 22 & 15 & \\ \mathrm{CZ05} & \mathrm{t}-\mathrm{ZrO}_{2} & 57 & 16 & 66 \\ & \mathrm{~m}-\mathrm{ZrO}_{2} & 43 & 12 & \\ \mathrm{CeO}_{2} & \mathrm{c}-\mathrm{CeO}_{2} & 100 & 12 & 55\end{array}$

The optical properties of CZ05 were measured by Diffuse Reflectance UV-Vis spectroscopy. Figure 1 compares the behavior of the mixed material with that of both pure oxides. The extreme features of this series are represented by the band gap transitions of zirconia and ceria which fall at 244 and $477 \mathrm{~nm}(5.08 \mathrm{eV}$ and $2.60 \mathrm{eV})$, respectively. The latter is due to the excitation of electrons from the VB to Ce 4 f orbital states ${ }^{14}$. The CZ05 UV-Vis absorption, even with such a low amount of ceria, shows a red shift in comparison to the band gap transition of $\mathrm{ZrO}_{2}$ with a weak tail in the visible. Remarkably, a solid produced by prolonged mechanical mixing of $\mathrm{ZrO}_{2}$ and $\mathrm{CeO}_{2}$ and having the same composition of $\mathrm{CZ05}$ has an optical behavior practically coincident with that of bare $\mathrm{ZrO}_{2}$ (magnification in Fig. 1B). This firmly indicates that the preparation procedure adopted favors an intimate interaction of $\mathrm{Ce}^{4+}$ and $\mathrm{ZrO}_{2}$ conferring peculiar optical properties to the mixed solid. 

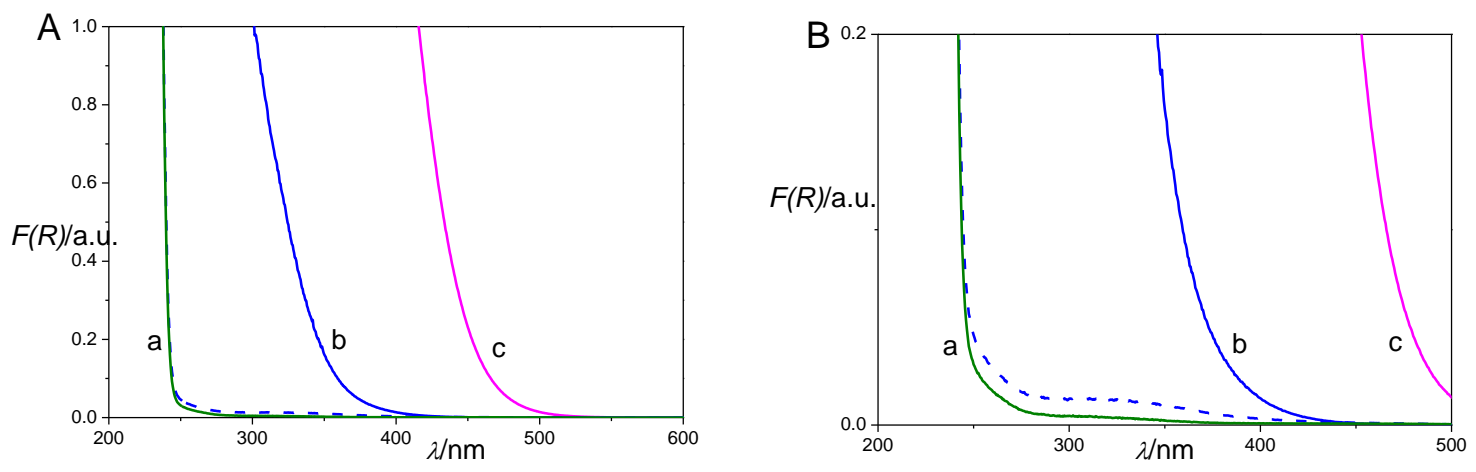

Figure 1. A) Absorption spectra of a) $\mathrm{ZrO}_{2}$, b) $\mathrm{CZ05}$, c) $\mathrm{CeO}_{2}$. B) magnification of $\mathrm{A}$. The dashed line is related to a mechanical mixture with the same composition of CZ05.

The photoactivity of the mixed material has been tested by EPR. This is a suitable technique to detect the charge separation, as shown by the seminal work of Graetzel and Howe ${ }^{15}$ and by that of the Thurnauer group ${ }^{16}$ who monitored by EPR the formation of both photoexcited electrons and holes in UV irradiated $\mathrm{TiO}_{2}$.

We have followed (Fig. 2A) the charge separation in the case of $\mathrm{Ce}-\mathrm{ZrO}_{2}$ using irradiation with visible light, that is applying a cut off to the lamp output at 420nm. The starting spectrum (Fig. 2A, a) does not show a flat baseline and the EPR signal observed (nearly axial with $\mathrm{g}_{\|}=1.977$ and $\mathrm{g}_{\perp}=1.959$ ) is the same observed in the case of bare $\mathrm{ZrO}_{2}$ and due to $\mathrm{Zr}^{3+}$ ions always present as defects in this solid ${ }^{17}$. Irradiation of the CZ05 sample at $77 \mathrm{~K}$ with light having $\lambda>420 \mathrm{~nm}$ (i.e. $\mathrm{h} v<2.95 \mathrm{eV}$ ) (Fig. 2A, b) causes the intensity increase of the $\mathrm{Zr}^{3+}$ signal and, in parallel, the appearance of a new signal due to trapped holes $\left(\mathrm{O}^{-}\right.$ions $)$at lower field ${ }^{17}$. Heating the system at RT, electrons and holes quickly recombine, recovering the initial situation. 

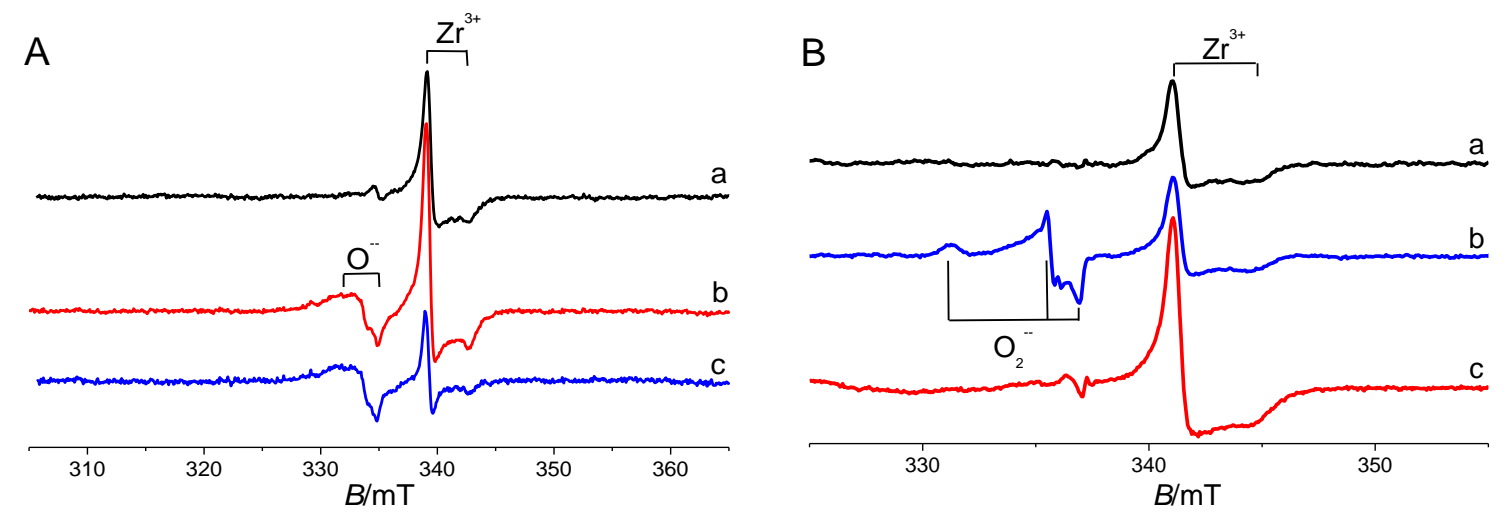

Figure 2. EPR spectra of CZ05 recorded at $77 \mathrm{~K}$ under irradiation with visible light $(\lambda>420 \mathrm{~nm})$. A: irradiation under vacuum (a, background; b, irradiation; $c$, difference spectrum(b-a)). B: irradiation in gas atmosphere ( $a$, background; b, O2; c, H2).

The effective charge separation occurring under irradiation is better evidenced by subtracting the background from the spectrum obtained upon irradiation. The spectrum (Fig. 2A, c) shows two equally intense and distinct signals $\left(\mathrm{O}^{-}, \mathrm{Zr}^{3+}\right)$ which derive from the charge separation. It is worth mentioning that this effect has been obtained using wavelengths belonging entirely to the visible light domain. The same experiment, performed on bare $\mathrm{ZrO}_{2}$, has scarcely appreciable effects (S.I.). The spectra in Fig. 2A are conceptually important as they clearly indicate that: a) the insertion of small amounts of cerium sensitizes the $\mathrm{ZrO}_{2}$ matrix to visible light and $b$ ) the visible-light excited electrons reach the conduction band of $\mathrm{ZrO}_{2}$ forming $\mathrm{Zr}^{3+}$ ions. This result is strengthened by parallel experiments (Fig. 2B) consisting in the irradiation of the material under an atmosphere of either $\mathrm{O}_{2}$ or $\mathrm{H}_{2}$ which allows to demonstrate that the generated charge carriers actually reach the surface of the nanoparticles. In the former case, in fact, $\mathrm{O}_{2}$ reacts with photogenerated electrons producing surface adsorbed superoxide, $\mathrm{O}_{2}^{-}$:

$$
\mathrm{e}_{(\mathrm{CB})}^{-}+\mathrm{O}_{2 \text { (gas) }} \rightarrow \mathrm{O}_{2(\text { ads })}^{-}
$$


Fig $2 \mathrm{~B}$, b shows the well-known signal of $\mathrm{O}_{2}{ }^{-}$adsorbed on the $\mathrm{ZrO}_{2}$ surface ${ }^{17}$ which proves that electrons photoexcited in conduction band have reached the surface.

In the second case, holes $\left(\mathrm{h}^{+}\right)$react with gas-phase hydrogen at the surface yielding surface $\mathrm{OH}^{-}$groups and injecting electrons in the solid ${ }^{18}$ which are stabilized by zirconium ions forming reduced $\mathrm{Zr}^{3+}$ centers:

$$
\begin{aligned}
& \mathrm{h}^{+}+\mathrm{O}^{2-}{ }_{\text {(surf) }} \rightarrow \mathrm{O}_{\text {(surf) }}^{-} \\
& \mathrm{O}_{\text {(surf) }}^{-}+\mathrm{H}_{2} \rightarrow \mathrm{OH}_{\text {(surf) }}^{-}+\mathrm{H}^{\cdot} \\
& \mathrm{H}^{\cdot}+\mathrm{O}^{2-}{ }_{\text {(surf) }}+\mathrm{Zr}^{4+} \rightarrow \mathrm{OH}_{\text {(surf) }}^{-}+\mathrm{Zr}^{3+}
\end{aligned}
$$

Fig. 2B, c reports the intensity increase of the $\mathrm{Zr}^{3+}$ signal (eq. 4) produced by visible light irradiation in $\mathrm{H}_{2}$ and attesting the presence of holes at the surface .

The two parallel experiments illustrated in Fig. 2B confirm that visible photons induce electron-hole separation in Ce-doped zirconia (Fig. 2A) adding the important information that both carriers reach the surface and are, in principle, available for surface reactions.

The potential photocatalytic activity of the $\mathrm{Ce}-\mathrm{ZrO}_{2}$ system in visible light was tested monitoring the formation of hydroxyl radicals $\left(\mathrm{HO}^{\bullet}\right)$ upon irradiation of a water suspension of the CZ05 sample. $\mathrm{HO}^{\bullet}$ radicals, which are responsible of the oxidative attack of organic molecules in photocatalytic reactions, are formed according to:

$$
\mathrm{h}^{+}+\mathrm{H}_{2} \mathrm{O} \rightarrow \mathrm{HO}^{\bullet}+\mathrm{H}^{+}
$$

Due to their reactivity, these radicals can only be detected in solution by means of a spin trap (namely the 5,5-dimethyl-1-pyrroline N-oxide, DMPO), a diamagnetic molecule which, by reaction with $\mathrm{HO}^{\circ}$, forms a relatively stable radical adduct detected by EPR. The detection of photoinduced $\mathrm{HO}^{\bullet}$ radicals is thus an evidence of the oxidative ability of an irradiated solid ${ }^{19}$. Figure 3A reports the EPR spectra obtained upon illumination of a CZ05 aqueous suspension 
with visible light at various times. All spectra are amenable to the typical four lines signal of the $\mathrm{DMPO} / \mathrm{HO}^{\bullet}$ adduct and have been obtained subtracting from the experimental spectrum that of a reference obtained irradiating a solution of DMPO. The reported spectra are thus entirely due to the effect of the solid material. Figure 3B shows that the intensity of the adduct becomes appreciable after $10 \mathrm{~min}$ irradiation and reaches a maximum after about $110 \mathrm{~min}$. Also in this case no effect is observed using pure $\mathrm{ZrO}_{2}$.
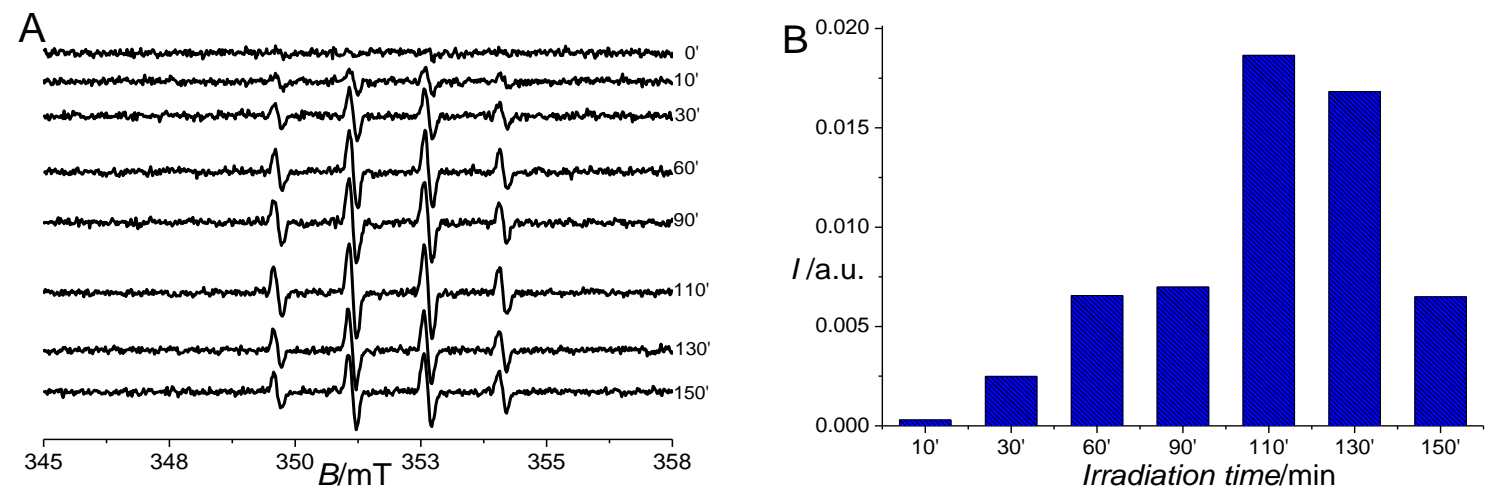

Figure 3. A. EPR spectra of the $\mathrm{DMPO} / \mathrm{HO}^{\bullet}$ adduct produced by irradiation of an aqueous suspension of CZ05 with Visible-NIR light $(\lambda>420 \mathrm{~nm})$ as a function of the irradiation time. B. Bar diagram of the corresponding EPR intensities.

The origin of the visible light photoactivity of Ce-doped $\mathrm{ZrO}_{2}$ can be understood based on DFT (B3LYP) calculations. Hybrid exchange-correlation functionals, making use of a combination of exact (as in HF) and DFT exchange terms, were shown in recent years to quite accurately reproduce experimental band gaps, which on the contrary are severely underestimated by local or semilocal functionals ${ }^{20}$. $\mathrm{Zr}$ and $\mathrm{Ce}$ atoms are isovalent. Therefore, the replacement of a $\mathrm{Zr}$ ion with a $\mathrm{Ce}$ ion in the same formal +4 oxidation state does not alter the charge neutrality of the system and does not result in extra electrons in the electronic structure. The incorporation of $\mathrm{Ce}$ in substitutional positions of the $\mathrm{ZrO}_{2}$ tetragonal lattice creates a series of unoccupied 
defect states in the band-gap (direct: $5.8 \mathrm{eV}, 5.6$ for the monoclinic phase), about 3.2-3.5 eV above the top of the VB, Figure 4 (Kohn-Sham energy levels). Projection of these bands onto the basis functions of the $\mathrm{Ce}$ atom indicates that they originate from the $\mathrm{Ce} 4 \mathrm{f}$ states and that are highly localized around Ce. Virtually no dispersion is observed for the case of an isolated Ce ion.

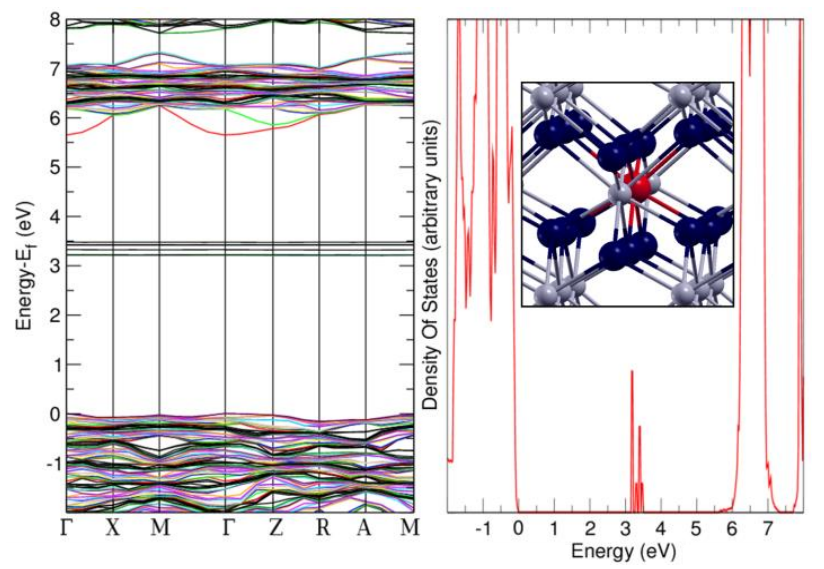

Figure 4. Band structure (left) and density of states (right) of a $3 \times 3 \times 2$ tetragonal $\mathrm{ZrO}_{2}$ supercell doped with a single substitutional $\mathrm{Ce}$ atom (inset).

Very important for the interpretation of the results is the calculation of the energies involved in electronic transitions stimulated by irradiation with visible light. It is common practice to estimate the semiconductor band gap and the energy levels introduced in the gap by defect centers using the single-particle Kohn-Sham eigenvalues. This approach, however, is not well justified if electronic transitions are involved. A more robust approach consists in the calculation of transition energy levels between different charge states for a defective system. The transition level $\varepsilon(q+1 / q)$ is defined as the Fermi-level, referred to the top of the valence band, for which the formation energies of defect in the charge states $q+1$ and $q$ are equal. In general, the transition energy levels can be derived from calculated total energies. With the CRYSTAL code used for the calculations, they are approximated, on the basis of Janak's theorem, from single particles eigenvalues $^{21}$. This method is rather accurate when used in connection with hybrid functionals 
that provide a good estimate of the Kohn-Sham band gap of the system ${ }^{22}$. In particular, optical transition levels $\left(\varepsilon^{\mathrm{opt}}\right)$ can be directly compared with the position of the defect levels estimated from optical excitation, Figure 5. Two transitions are of particular importance here:

$$
\begin{aligned}
& \mathrm{O}^{2-}{ }_{(\mathrm{VB})}+\mathrm{Ce}^{4+} \rightarrow \mathrm{O}^{-}{ }_{(\mathrm{VB})}+\mathrm{Ce}^{3+} \\
& \mathrm{Ce}^{3+}+\mathrm{Zr}^{4+}{ }_{(\mathrm{CB})} \rightarrow \mathrm{Ce}^{4+}+\mathrm{Zr}^{3+}{ }_{(\mathrm{CB})}
\end{aligned}
$$

The results show that the transition from the VB to a $\mathrm{Ce}^{4+}$ cation, eq. 6 , leading to a $\mathrm{Ce}^{3+}$ ion, occurs at $2.5 \mathrm{eV}$, i.e. well inside the visible light spectrum. A second excitation can occur from these states with an electron transfer from $\mathrm{Ce}^{3+}$ to the $\mathrm{CB}$, eq. 7 : in this case, the optical transition is found at $3.3 \mathrm{eV}(3.1+0.2 \mathrm{eV}$, Fig 5) i.e. at the limit of the visible light radiation (the $0.2 \mathrm{eV}$ contribution is due to the formation of localized $\mathrm{Zr}^{3+}$ states just below the $\mathrm{CB}$ minimum, as discussed in ref. 17). This second excitation value is probably too large since the B3LYP method overestimates the conduction band minimum (CBM) energy and thus the band gap of $\mathrm{ZrO}_{2}$ by $14 \%$ (KS gap $5.8 \mathrm{eV}$, Fig. 5, experimental optical transition $5.1 \mathrm{eV}$, Fig. 1). Therefore, we propose these transitions from the VBM (valence band maximum) to the $\mathrm{Ce}^{4+}$ states and from the $\mathrm{Ce}^{3+}$ states to the $\mathrm{CBM}$ to be at the origin of the optical absorption spectrum in Fig. $1 \mathrm{~b}$ (where the absorption edge of the doped sample falls below the $3 \mathrm{eV}$ threshold) and consequently of the formation of $\mathrm{O}^{-}$and $\mathrm{Zr}^{3+}$ species observed experimentally under visible light irradiation 


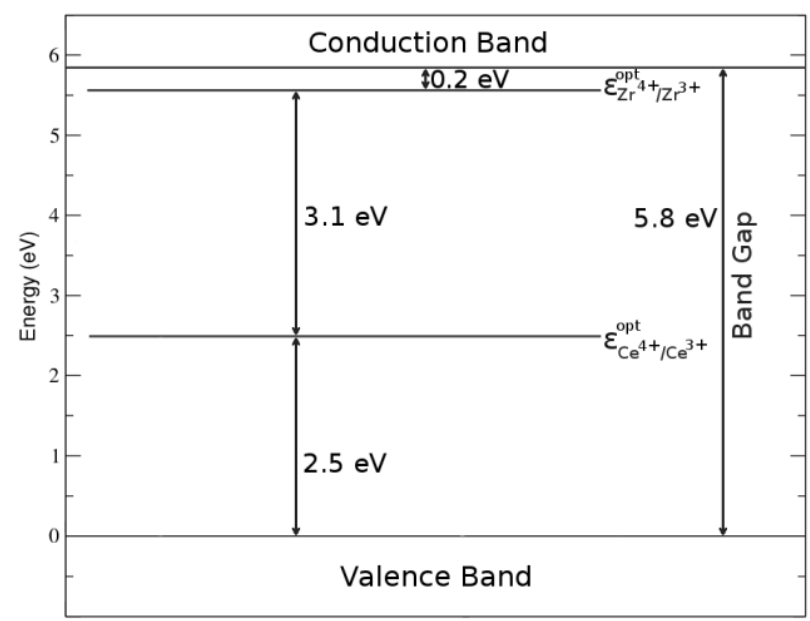

Figure 5. Optical transition levels for a $3 \times 3 \times 2$ tetragonal $\mathrm{ZrO}_{2}$ supercell doped with a single $\mathrm{Ce}$ atom dopant. The position of both mid gap $\mathrm{Ce}^{3+}$ states and defective $\mathrm{Zr}^{3+}$ ones is indicated.

To conclude, the set of data discussed above indicates that it is possible, through the dispersion of small amounts of cerium ions, to make $\mathrm{ZrO}_{2}$ photosensitive to visible light. Based on the available experimental and theoretical data, a possible explanation points to the role of intraband gap Ce $4 \mathrm{f}$ empty states which could act as a bridge between the valence band and the conduction band of the oxide allowing low-energy photons to excite electrons from one band to the other. The mechanism corresponds to one of the two proposed by Serpone et al. while forecasting the nature of third generation photocatalysts ${ }^{5,6} \cdot \mathrm{Ce}-\mathrm{ZrO}_{2}$ can therefore be considered as the first member of this new family. Despite the system described shows an effective photoactivity, the results presented represent a "proof of concept" and show that this new class of photo-active materials can indeed be prepared. Further work is necessary to identify the optimal working conditions (Ce loading, crystal structure and morphology, preparation procedures etc.) and to optimize the activity and selectivity performances of the present system not only under visible light but also under real solar light irradiation. 


\section{EXPERIMENTAL METHODS}

Mixed Ce-Zr oxides were prepared via sol-gel synthesis using $\mathrm{Ce}$ isopropoxide and $\mathrm{Zr}$ propoxide solutions and following a complex procedure fully described in the S.I. The sol produced by hydrolysis was aged in air until the formation of a gel which was then dried at $333 \mathrm{~K}$. Finally the powder was calcined at $723 \mathrm{~K}$ in air for 2 hours.

Details on the experimental characterization methods, namely Powder X-rays diffraction (XRD), surface area measurements, Diffuse Reflectance UV-Vis (DR-UV-Vis) spectroscopy, EPR spectroscopy and Spin Trapping are available as S.I.

Spin-polarized periodic DFT (B3LYP) calculations were performed using the CRYSTAL09 code, based on a linear combination of atomic orbitals (LCAO). Further details on the models, the basis sets and the computation of the transition energy levels are illustrated in S. I.

\section{ASSOCIATED CONTENT}

Supporting Information. Additional information are available on (1) synthesis procedure; (2) experimental methods; (3) computational details; (4) X-ray diffraction patterns; (5) optical activity of physical mixtures; (6) additional calculations on the effect of Ce concentration. This material is available free of charge via the Internet at http://pubs.acs.org.

\section{AUTHOR INFORMATION}

\section{Corresponding Author}

*Email: elio.giamello@unito.it

\section{Notes}

The authors declare no competing financial interests. 


\section{ACKNOWLEDGMENT}

This work has been supported by the Italian Ministry of University and Research, MIUR, through the "Programs of National Relevance" (PRIN-2009); the "National Funding for Basic Research" (FIRB) with a project entitled "Oxides at the nanoscale: functionalities and applications" (FIRB RBAP11AYN).

\section{REFERENCES}

(1) Fujishima, A.; Zhang, X.; Tryk, D. A. $\mathrm{TiO}_{2}$ Photocatalysis and Related Surface Phenomena. Surf. Sci. Rep. 2008, 63, 515-582.

(2) Hagfeldt, A.; Gratzel, M. Light-Induced Redox Reactions in Nanocrystalline Systems. Chem. Rev. 1995, 95, 49-68.

(3) Fujishima, A.; Honda, K. Electrochemical Photolysis of Water at a Semiconductor Electrode. Nature 1972, 238, 37-38.

(4) Gust, D.; Moore, T. A.; Moore, A. L. Solar Fuels via Artificial Photosynthesis. Acc. Chem. Res. 2009, 42, 1890-1898.

(5) Emeline, A. V.; Kuznetsov, V. N.; Ryabchuk, V. K.; Serpone, N. On the Way to the Creation of Next Generation Photoactive Materials. Environ. Sci. Pollut. Res. 2012, 19, 36663675 .

(6) Serpone, N.; Emeline, A. V. Semiconductor Photocatalysis - Past, Present, and Future Outlook. J. Phys. Chem. Lett. 2012, 3, 673-677.

(7) Linsebigler, A. L.; Lu, G. Q.; Yates, J. T. Photocatalysis on $\mathrm{TiO}_{2}$ Surfaces - Principles, Mechanisms, and Selected Results. Chem. Rev. 1995, 95, 735-758.

(8) Takeuchi, M.; Yamashita, H.; Matsuoka, M.; Anpo, M.; Hirao, T.; Itoh, N.; Iwamoto, N. Photocatalytic Decomposition of NO Under Visible Light Irradiation on the Cr-Ion-Implanted $\mathrm{TiO}_{2}$ Thin Film Photocatalyst. Catal. Lett. 2000, 67, 135-137.

(9) Asahi, R.; Morikawa, T.; Ohwaki, T.; Aoki, K.; Taga, Y. Visible-Light Photocatalysis in Nitrogen-Doped Titanium Oxides. Science 2001, 293, 269-271.

(10) Livraghi, S.; Paganini, M. C.; Giamello, E.; Selloni, A.; Di Valentin, C.; Pacchioni, G. Origin of Photoactivity of Nitrogen-Doped Titanium Dioxide Under Visible Light. J. Am. Chem. Soc. 2006, 128, 15666-15671.

(11) Barolo, G.; Livraghi, S.; Chiesa, M.; Paganini, M. C.; Giamello, E. Mechanism of the Photoactivity under Visible Light of N-Doped Titanium Dioxide. Charge Carriers Migration in Irradiated $\mathrm{N}-\mathrm{TiO}_{2}$ Investigated by Electron Paramagnetic Resonance. J. Phys. Chem. C 2012, 116, 20887-20894.

(12) Warren, S. C.; Thimsen, E. Plasmonic Solar Water Splitting. Energy Environ. Sci. 2012, 5, 5133-5146.

(13) Kohno, Y.; Tanaka, T.; Funabiki, T.; Yoshida, S. Identification and Reactivity of a Surface Intermediate in the Photoreduction of $\mathrm{CO}_{2}$ with $\mathrm{H}_{2}$ over $\mathrm{ZrO}_{2}$. J. Chem. Soc. Faraday Trans. 1998, 94, 1875-1880.

(14) Da Silva, J. L. F.; Ganduglia-Pirovano, M. V.; Sauer, J.; Bayer, V.; Kresse, G. Hybrid Functionals Applied to Rare-Earth Oxides: the Example of Ceria. Phys. Rev. B 2007, 75, 035109. 
(15) Howe, R. F.; Gratzel, M. Electron-Paramagnetic-Resonance Study of Hydrated Anatase Under UV Irradiation. J. Phys. Chem. 1987, 91, 3906-3909.

(16) Micic, O. I.; Zhang, Y. N.; Cromack, K. R.; Trifunac, A. D.; Thurnauer, M. C. Photoinduced Hole Transfer from $\mathrm{TiO}_{2}$ to Methanol Molecules in Aqueous-Solution Studied by Electron-Paramagnetic-Resonance. J. Phys. Chem. 1993, 97, 13284-13288.

(17) Gionco, C.; Paganini, M. C.; Giamello, E.; Burgess, R.; Di Valentin, C.; Pacchioni, G. Paramagnetic Defects in Polycrystalline Zirconia: An EPR and DFT Study. Chem. Mater. 2013, 25, 2243-2253.

(18) Livraghi, S.; Chiesa, M.; Paganini, M. C.; Giamello, E. On the Nature of Reduced States in Titanium Dioxide As Monitored by Electron Paramagnetic Resonance. I: The Anatase Case. $J$. Phys. Chem. C 2011, 115, 25413-25421.

(19) Dvoranova, D.; Brezova, V.; Mazur, M.; Malati, M. A. Investigations of Metal-Doped Titanium Dioxide Photocatalysts. Appl. Catal. B 2002, 37, 91-105.

(20) Muscat, J.; Wander, A.; Harrison, N. M. On the Prediction of Band Gaps from Hybrid Functional Theory. Chem. Phys. Lett. 2001, 342, 397-401.

(21) Gallino, F.; Pacchioni, G.; Di Valentin, C. Transition Levels of Defect Centers in ZnO by Hybrid Functionals and Localized Basis Set Approach. J. Chem. Phys. 2010, 133, 144512.

(22) Oba, F.; Togo, A.; Tanaka, I.; Paier, J.; Kresse, G. Defect Energetics in ZnO: A Hybrid Hartree-Fock Density Functional Study. Phys. Rev. B 2008, 77, 245202. 